\title{
Increased urinary lgM excretion in patients with chest pain due to coronary artery disease
}

\author{
Rafid Tofik ${ }^{1,2}$, Ulf Ekelund ${ }^{1,2}$, Ole Torffvit ${ }^{2}$, Per Swärd ${ }^{2}$, Bengt Rippe ${ }^{2}$ and Omran Bakoush ${ }^{2,3^{*}}$
}

\begin{abstract}
Background: Micro-albuminuria is a recognized predictor of cardiovascular morbidity and mortality in patients with coronary artery disease. We have previously reported, in diabetic and non-diabetic patients, that an increased urinary excretion of IgM is associated with higher cardiovascular mortality. The purpose of this study was to investigate the pattern of urinary IgM excretion in patients with acute coronary syndrome (ACS) and its correlation to cardiovascular outcome.

Methods: Urine albumin, and IgM to creatinine concentration ratios were determined in 178 consecutive patients presenting with chest pain to the Department of Emergency Medicine (ED) at the University Hospital of Lund. Fifty eight (23 female) patients had ACS, 55 (19 female) patients had stable angina (SA), and 65 (35 female) patients were diagnosed as non-specific chest pain (NS).

Results: Urine albumin and IgM excretions were significantly higher in patients with ACS ( $p=0.001$, and $p=0.029$, respectively) compared to patients with NS-chest pain. During the 2 years follow-up time, 40 (19 female) patients suffered a new major cardiovascular event (ACS, acute heart failure, stroke) and 5 ( 4 male/1 female) patients died of cardiovascular cause. A high degree of albuminuria and IgM-uria significantly predicted cardiovascular mortality and morbidity ( $\mathrm{HR}=2.89,95 \% \mathrm{Cl}: 1.48-5.66, \mathrm{p}=0.002$ ). Microalbuminuric patients ( $\geq 3 \mathrm{mg} / \mathrm{mmo}$ ) with high IgM-uria $(\geq 0.005 \mathrm{mg} / \mathrm{mmol}$ ) had a 3-fold higher risk for cardiovascular new events compared to patients with low IgM-uria ( $R R=3.3,95 \%$ Cl: $1.1-9.9, p=0.001)$.
\end{abstract}

Conclusion: In patients with chest pain, an increased urine IgM excretion, is associated with coronary artery disease and long-term cardiovascular complications. Measuring urine lgM concentration could have a clinical value in risk stratification of patients with ACS.

Keywords: Urine IgM, Microalbuminuria, Acute coronary syndrome, Chest pain, Cardiovascular mortality

\section{Background}

The number of patients presenting to the emergency department (ED) with symptoms consistent with acute coronary syndrome (ACS) is rising [1,2]. Medical history and ECG findings are widely used and reliable keystones in risk stratification of patients presenting with chest pain $[3,4]$. However, many patients who are admitted to the medical ward due to chest pain will not turn out to suffer from acute coronary syndrome (ACS) [5]. Thus better tools for risk stratification are needed.

ACS is associated with increased urinary albumin excretion [6,7]. Microalbuminuria (MA) has been recognized as

\footnotetext{
* Correspondence: Omran.Bakoush@med.lu.se

2Department of Nephrology, Lund University, Lund, Sweden

${ }^{3}$ Department of Internal Medicine, UAE University, Al Ain, UAE

Full list of author information is available at the end of the article
}

an independent prognostic marker for poor outcome in patients with coronary artery disease (CAD) [8]. MA could reflect widespread endothelial dysfunction due to atherosclerotic disease [9], with relative lack of endothelial nitric oxide (NO) production and increased levels of oxidative stress [10]. Long-term follow up studies on proteinuric patients have revealed that IgM-uria may be associated with a higher risk for cardiovascular (CV) mortality [11-13]. For instance, type 2 diabetic patients with MA and IgMuria had a 3-fold higher risk for $\mathrm{CV}$ mortality than patients with merely MA. To the best of our knowledge, IgM-uria has not been studied in patients with CAD. Therefore, in this cohort of patients presenting with chest pain to the emergency department (ED) we studied the diagnostic and prognostic value of IgM-uria.

\section{Ciomed Central}




\section{Methods}

Consecutive patients presenting with symptoms suggestive of ACS, to the ED at Skåne University Hospital in Lund during 53 daytime working shifts between September $1^{\text {st }}$ and December $31^{\text {st }} 2010$, were invited to participate in the study. The study was carried out in compliance with the Helsinki Declaration, and was approved by the Regional Ethical Review Board of Lund (Dnr 2009/441).

After informed consent, 178 (77 female) consecutive patients with chest pain were included in the study. The patients were further assessed by the attending physician. The physician assessment included history, physical examination, 12-lead electrocardiography (ECG) and cardiac Troponin T (TNT) assay. Vital signs were measured in supine position at admission to the ED. Mean arterial blood pressure (MAP) was calculated by adding one third of the pulse pressure to the diastolic blood pressure. All participants were asked at the time of admission to provide urine samples for urine protein analysis.

65 patients (35 female) with normal 12-lead ECGs and normal plasma TNT levels were discharged to go home after a few hours of observation in the ED (Table 1). 113 (46 female) patients were admitted to the medical ward with suspected acute coronary syndrome (ACS). Cardiac stress test (including exercise test or myocardial scintigraphy) was done in ambiguous cases $(\mathrm{n}=36)$.

The final diagnosis was retrieved from the discharge notes of the patient's medical records. Patients who were diagnosed with ACS were those with acute ST-elevation (STEMI) or non ST-elevation myocardial infarction (NSTEMI) or unstable angina. Patients with a previous history of cardiovascular event (angina, acute myocardial infarction (AMI), stroke), with no emerging ECG changes

Table 1 Baseline characteristics and two-year cardiovascular outcome of 178 patients presented with chest pain to the emergency department divided into 3 groups according to the clinical diagnosis of coronary artery disease

\begin{tabular}{|c|c|c|c|c|}
\hline & $\begin{array}{l}\text { Acute coronary syndrome } \\
\qquad \begin{array}{c}\text { (ACS) } \\
n=58\end{array}\end{array}$ & $\begin{array}{c}\text { Stable Angina } \\
\text { (SA) } \\
n=55\end{array}$ & $\begin{array}{c}\text { Non-specific chest pain } \\
\text { (NS) } \\
n=65\end{array}$ & $\begin{array}{c}\text { P value } \\
\text { (ACS vs. NS) }\end{array}$ \\
\hline Age, yr & $76(52-98)$ & $70(39-91)$ & $62(40-92)$ & $<0.001$ \\
\hline Sex, $n$ & $35 / 23$ & $36 / 19$ & $30 / 35$ & 0.1 \\
\hline P. creatinine, $\mu \mathrm{mol} / \mathrm{L}$ & $86.5(56-249)$ & $85(49-259)$ & $75(49-166)$ & $<0.001$ \\
\hline MAP, $m m H g$ & $106.7(77-139)$ & $105(81-140)$ & $105(82-140)$ & 0.7 \\
\hline BMI & $25(16.7-38.8)$ & $27.6(20.8-43.1)$ & $27.2(20.9-42.7)$ & 0.043 \\
\hline Smoking, $\%$ & 27.6 & 16.4 & 26.2 & 0.1 \\
\hline Hypertension,\% & 67.2 & 81.8 & 27.7 & $<0.001$ \\
\hline Family history, $\%$ & 41.4 & 43.6 & 32 & 0.1 \\
\hline DM (type 1/type 2) & $10(2 / 8)$ & $18(0 / 18)$ & $6(0 / 6)$ & 0.2 \\
\hline LDL cholesterol, mmol/L & $3(1.3-5.4)$ & $2.2(1-5)$ & $3.2(1.8-5)$ & 0.5 \\
\hline $\mathrm{TGL}, \mathrm{mmol} / \mathrm{L}$ & $1.25(0.6-6.6)$ & $1.25(0.6-3.5)$ & $1.55(0.7-4)$ & 0.2 \\
\hline P. $\lg M, g / l$ & $0.76(0.2-3.5)$ & $0.73(0.05-1.5)$ & $0.71(0.27-4.9)$ & 0.9 \\
\hline \multirow[t]{2}{*}{ IgM-uria, mg/mmol } & 0.0066 & 0.0058 & 0.0046 & 0.029 \\
\hline & $(0.00027-0.249)$ & $(0.00075-0.0549)$ & $(0.00098-0.0716)$ & \\
\hline Albuminuria, $\mathrm{mg} / \mathrm{mmol}$ & $2(0.1-247)$ & $0.6(0.1-59)$ & $0.1(0.1-70)$ & 0.001 \\
\hline lgG-uria, mg/mmol & $2.1(0.1-89)$ & $1.6(0.1-6.6)$ & $1.6(0.1-11)$ & 0.06 \\
\hline CRP, mg/l & $3.1(0.6-80)$ & $1.4(0.6-24)$ & $1.6(0.6-33)$ & 0.012 \\
\hline TNT, ng/l & $24(5-1168)$ & $9(5-419)$ & $5(5-44)$ & $<0.001$ \\
\hline Admitted, $n(m / f)$ & $53(34 / 19)$ & $28(16 / 12)$ & $32(17 / 15)$ & $<0.001$ \\
\hline \multirow[t]{6}{*}{ CV outcome at 2 years follow up, $n(m / f)$} & $27(16 / 11)$ & $12(6 / 6)$ & $6(3 / 3)$ & $<0.001$ \\
\hline & Death $=3(2 / 1)$ & Death $=2(2 / 0)$ & Death $=0$ & \\
\hline & $\mathrm{AMI}=8(5 / 3)$ & $\mathrm{AMI}=3(1 / 2)$ & $\mathrm{AMI}=3(2 / 1)$ & \\
\hline & Angina $=9(5 / 4)$ & Angina $=3(1 / 2)$ & Angina $=1(0 / 1)$ & \\
\hline & $\mathrm{CVI}=1(0 / 1)$ & $C V I=0$ & $\mathrm{CVI}=1(1 / 0)$ & \\
\hline & $H F=6(4 / 2)$ & $\mathrm{HF}=4(2 / 2)$ & $\mathrm{HF}=1(0 / 1)$ & \\
\hline
\end{tabular}


and normal TNT levels were diagnosed as stable angina (SA). Patients with atypical anginal chest pain with no history of previous cardiovascular event with normal ECG and TNT series were diagnosed as non-specific chest pain (NS).

The patients were followed up to the end of February 2012 for occurrence of any major cardiovascular event such as death, MI, and stroke. Cardiovascular death was defined as all deaths where unequivocal non-CV death was not established.

\section{Laboratory methods}

The plasma and urine creatinine (enzymatic method), serum and urine proteins, and serum lipids were analyzed at the Central Clinical Chemistry Laboratory at the University Hospital in Lund, for details see [14,15]. Patients were defined as having dyslipidemia if serum low density lipoprotein cholesterol $>3 \mathrm{mmol} / \mathrm{L}$ and/or serum triglycerides level $>1.7 \mathrm{mmol} / \mathrm{L}$ [16]. Urinary albumin concentration was measured by immunoturbidometry on fresh urine samples taken at the time of patient admission. We used a Cobas Mira S system (Roche Inc.) and monospecific rabbit antisera obtained from Dako (Copenhagen, Denmark). Urine samples were stored in $3.5-\mathrm{ml}$ polypropene tubes and kept at $-20 \mathrm{C}$ until analysis for IgM. Urine IgM concentrations were measured by an ELISA technique described in detail elsewhere [17]. The lower detection limit for the urine IgM assay is $1 \mu \mathrm{g} / \mathrm{l}$; the intra-assay and inter-assay variation is $4.6 \%$ and $10.9 \%$, respectively.

Urine albumin, and IgM are presented as albumin, and IgM-creatinine ratios $\mathrm{mg} / \mathrm{mmol}$ (ACR and MCR), respectively. The lowest detection level of ACR is $0.1 \mathrm{mg} / \mathrm{mmol}$. The median value of urine IgM concentration of the whole cohort was $0.005 \mathrm{mg} / \mathrm{mmol}$. Patients were divided into low and high IgM-uria groups according to the cohort median concentration.

\section{Statistical methods}

Data are presented as medians (and ranges). Statistically significant levels were set considering 95\% confidence intervals $(\mathrm{CI})$ and a $\mathrm{P}$ value $<0.05$. Kruskal-Wallis $\mathrm{H}$ and Mann-Whitney $U$ tests were used to compare groups. Kaplan-Meier curves (for survival analysis) and Log Rank test were used to assess differences in survival. Coxproportional hazards regression analysis was employed to assess the association of baseline variables and cardiovascular outcome. Patients with missing data were excluded. All statistical analyses were performed by using IBM SPSS statistics for Windows, version 17.0 (SPSS).

\section{Results}

Fifty eight (23 female) patients had acute coronary syndrome. 3 (1 female) patients with STEMI, 25 (8 female) with NSTEMI and 30 (14 female) patients had unstable angina. Fifty five (19 female) patients had SA. Sixty five (35 female) patients were diagnosed as NS.

There was no difference in gender, mean arterial blood pressure, smoking, and family history of IHD between patients with ACS and NS chest pain (Table 1). Patients with ACS were older with higher prevalence of hypertension, worse kidney function and higher hs-CRP than NS patients. Urine albumin and urine IgM excretions were higher in patients with ACS than those with NS $(p=0.001$ and $p=0.029$, respectively), as shown in Table 1 . However, there was no difference in urine IgM or urine albumin excretion between patients with SA and NS $(P=0.3, P=0.2$, $n s)$ or between patients who performed the stress test or $\operatorname{not}(P=0.3, P=0.5, n s)$.

During a 2 year follow-up, 5 ( 1 female) patients died from a cardiovascular cause and 40 (19 female) patients suffered a new major cardiovascular event, (Table 1).

\section{Albumiuria and IgM-uria in risk stratification of patients with chest pain}

By univariate Cox-regression analysis the predictors for major cardiovascular events were: age $(\mathrm{HR}=1.031)$, hypertension $(\mathrm{HR}=2.38)$, previous ischemic heart disease $(\mathrm{HR}=$ 4.33) hs-CRP ( $\mathrm{HR}=1.87)$, TNT ( $\mathrm{HR}=2.02)$, albuminuria $(\mathrm{HR}=1.87)$, and IgM-uria $(\mathrm{HR}=2.96)$, Table 2. Diabetes, dyslipidemia, and level of kidney function were not associated with the cardiovascular outcome in this cohort (Table 2).

In a multivariate Cox-regression analysis, a significant association remained between IgM-uria and the cardiovascular outcome even after adjustment for key potential confounding variables: age, hypertension, previous

\begin{tabular}{|c|c|c|c|c|c|}
\hline Variable & Beta & SE & P-value & HR & $95 \% \mathrm{Cl}$ \\
\hline Age (2 groups) & 0.86 & 0.32 & 0.007 & 2.37 & $1.26-4.46$ \\
\hline Hypertension (yes/no) & 0.79 & 3.33 & 0.018 & 2.22 & $1.14-4.29$ \\
\hline Prev. cv disease (yes/no) & 1.33 & 3.37 & $<0.001$ & 3.78 & $1.82-7.85$ \\
\hline DM (yes/no) & -0.48 & 0.44 & 0.27 & 0.62 & $0.26-1.46$ \\
\hline Dyslipidemia (yes/no) & -0.25 & 0.32 & 0.43 & 0.78 & $0.42-1.45$ \\
\hline hs-CRP (2 groups) & 0.65 & 0.30 & 0.034 & 1.91 & $1.05-3.48$ \\
\hline Plasma TNT (2 groups) & 0.7 & 0.32 & 0.026 & 2.02 & $1.09-3.76$ \\
\hline S. creatinine (2 groups) & 0.24 & 0.3 & 0.43 & 1.27 & $0.71-2.29$ \\
\hline Albuminuria (2 groups) & 0.99 & 0.30 & 0.001 & 2.68 & $1.48-4.85$ \\
\hline IgM-uria (2 groups) & 1.08 & 0.34 & 0.001 & 2.96 & $1.52-5.77$ \\
\hline
\end{tabular}

Beta: Regression coefficient, SE: Standrad error of regression, HR: Hazard ratio, 95\% CI: 95\% confidence interval, DM: Diabetes mellitus, IgM-uria: Urine IgM creatinine ratio, hs-CRP: High sensitive C-reactive protein, TNT: Troponin T. Prev. cv disease: Previous cardiovascular disease. 
cardiovascular event, kidney function, and albuminuria, $(\mathrm{HR}=2.1,95 \%$ CI $1.05-4.01, \mathrm{p}=0.04)$.

In Kaplan Meier curve analysis, patients with MA $(\geq 3 \mathrm{mg} / \mathrm{mmol})$ and high levels of IgM-uria $(\geq 0.0054 \mathrm{mg} /$ $\mathrm{mmol}$ ) had a three-fold higher risk of new cardiovascular events than patients with MA and low-grade IgM-uria $(\mathrm{RR}=3.3,95 \% \mathrm{CI}: 1.1-9.9, \mathrm{p}=0.001)$ (Figure 1).

\section{Discussion}

In this prospective study, we found that patients who presented to the ED with chest pain due to acute coronary artery disease had a higher level of MA and IgM-uria than those with non-specific chest pain. Indeed, IgM-uria was associated with a higher risk of occurrence of subsequent major cardiovascular events. Furthermore, IgM-uria predicted poor long term cardiovascular outcome, independently of levels of MA, kidney function, diabetes and hypertension.

Under normal conditions the glomerular filtration barrier (GFB) allows just tiny amounts of albumin (molecular radius $35.5 \AA$ ) to pass to the primary urine, just one molecule out of 10,000 [18]. More than $97 \%$ of the filtered molecules are normally subsequently reabsorbed by the proximal tubules $[19,20]$. However, the GFB is not a static filter, but rather a highly dynamic sieve, which can directly increase its permeability in systemic inflammation [21], after trauma [22], during hyperglycemia [23], or following elevations of circulating ANP (atrial natriuretic peptide) levels [24], or angiotensin II levels [25]. Our data strongly suggest that albumin and other large proteins, such as IgG (mol. radius $55 \AA$ ) and IgM (mol. radius $120 \AA$ ) are able to pass the GFB only through large size-selective defects, "large pores" (shunts). An increased number of such shunt-like pores will functionally form in all of the pathophysiological conditions listed above resulting in albuminuria, IgG-uria and IgM-uria, while, at least initially, urinary tubular markers will stay unchanged. Consequently, the increased urinary IgM concentrations seen in patients with CAD must be secondary to decreases in size-selectivity of the GFB. Such size-selective defects are likely to be caused by endothelial dysfunction (due to atherosclerosis), acute systemic inflammation and/or ischemic (or HFinduced) release of ANP $[20,24,26]$. This is further strengthened by the fact that elevations of hs-CRP, reflecting systemic inflammation associated with atherosclerosis [27], and troponin T, more reflecting cardiac muscle ischemia, were coupled to the presence of CAD $[28,29]$ and to MA and IgM-uria, in turn signaling a poor cardiovascular outcome [12,13]. Unfortunately, it is likely that the method for assessing IgG urine concentration may not have been sensitive enough compared with the methods for MA and IgM-uria, since IgG-uria was not as strongly coupled to predictions of outcome

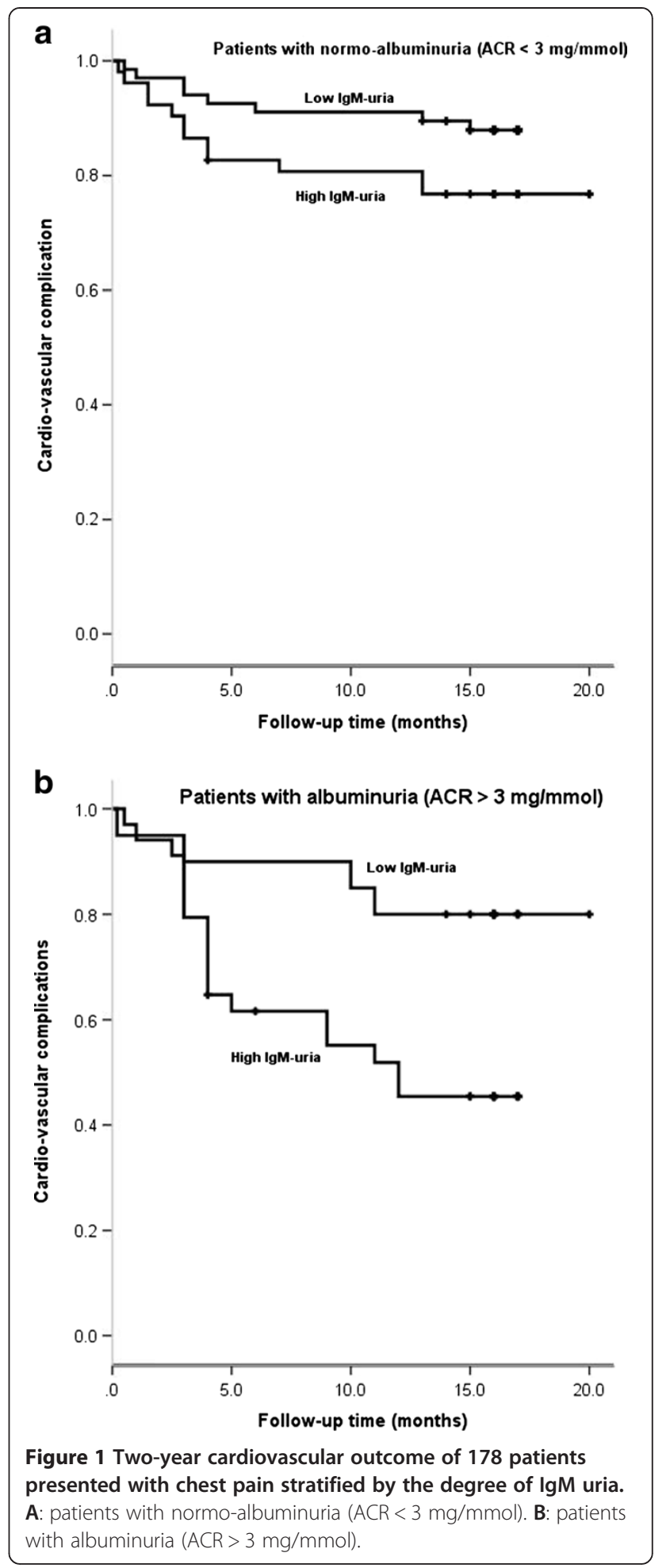

as were MA and IgM-uria. Urine IgM analysis is a simple, non-invasive urine test that could be incorporated in the routine laboratory analysis, for risk stratification of patients with chest pain [5,30]. Addition of urine IgM analysis to the workup of patients with coronary artery 
disease could help to identify patients at higher risk of recurrent cardiovascular events. This prompts early introduction of an intensive multifactorial preventive treatment strategy to improve the overall cardiovascular risk profile [31].

The study is limited by its observational nature. It was conducted in one centre and the participants were almost only of Scandinavian origin. However, our study has more than a few strengths. First, the patients were included prospectively and consecutively. Second, the study has a relatively long follow up time. Third, there was no loss of subjects during the follow up. Furthermore, urine IgM was measured during the first doctor contact in the ED.

\section{Conclusion}

In conclusion, patients with chest pain, with MA and high levels of IgM-uria carry a higher probability for coronary artery disease and a poorer long-term cardiovascular outcome than patients with low IgM-uria. A larger longitudinal confirmatory study is needed to evaluate the usefulness of urine IgM in risk stratification of patients with Coronary Artery Disease.

\section{Competing interests}

The authors declare that they have no competing interests.

\section{Authors' contributions}

RT and OB designed the study, analyzed the data, and draft the manuscript. UE, OT, PS, BR, contributed to the design of the study and drafting the manuscript. All authors read and approved the final manuscript.

\section{Acknowledgements}

This study was in part supported by the Swedish Research Council (grant 08285), the Swedish Heart and Lung Foundation and the Swedish government (ALF grants). We wish to thank the physicians and nurses at the Emergency clinic and Coronary care unit for assisting in collecting the patients' data. The skillful secretarial assistance by Kerstin Wihlborg is greatly acknowledged.

\section{Author details}

'Department of Emergency Medicine, Lund University, Lund, Sweden. ${ }^{2}$ Department of Nephrology, Lund University, Lund, Sweden. ${ }^{3}$ Department of Internal Medicine, UAE University, Al Ain, UAE.

Received: 8 November 2012 Accepted: 11 September 2013 Published: 13 September 2013

\section{References}

1. Goodacre S, Cross E, Arnold J, Angelini K, Capewell S, Nicholl J: The health care burden of acute chest pain. Heart 2005, 91:229-230.

2. Niska R, Bhuiya F, Xu J: National Hospital Ambulatory Medical Care Survey: 2007 emergency department summary. Natl Health Stat Report 2010, 26:1-31.

3. Wright RS, Anderson JL, Adams CD, Bridges CR, Casey DE Jr, Ettinger SM, Fesmire FM, Ganiats TG, Ineid H, Lincoff AM, et al: ACCF/AHA focused update of the Guidelines for the Management of Patients with Unstable Angina/Non-ST-Elevation Myocardial Infarction (updating the 2007 guideline): a report of the American College of Cardiology Foundation/ American Heart Association Task Force on Practice Guidelines developed in collaboration with the American College of Emergency Physicians, Society for Cardiovascular Angiography and Interventions, and Society of Thoracic Surgeons. J Am Coll Cardiol 2011, 57:1920-1959.
4. Elmehdawi RR, Albarsha AM: Obesity in Libya: a review. Libyan J Med 2012, 7:19086.

5. Ekelund U, Nilsson HJ, Frigyesi A, Torffvit O: Patients with suspected acute coronary syndrome in a university hospital emergency department: an observational study. BMC Emerg Med 2002, 2:1.

6. Gosling P, Hughes EA, Reynolds TM, Fox JP: Microalbuminuria is an early response following acute myocardial infarction. Eur Heart J 1991, 12:508-513.

7. Weir MR: Microalbuminuria and cardiovascular disease. Clin J Am Soc Nephrol 2007, 2:581-590.

8. Solbu MD, Kronborg J, Jenssen TG, Njolstad I, Lochen ML, Mathiesen EB, Wilsgaard T, Eriksen BO, Toft I: Albuminuria, metabolic syndrome and the risk of mortality and cardiovascular events. Atherosclerosis 2009, 204:503-508.

9. Liu CS, Pi-Sunyer FX, Li Cl, Davidson LE, Li TC, Chen W, Lin CC, Huang CY, $L$ in WY: Albuminuria is strongly associated with arterial stiffness, especially in diabetic or hypertensive subjects-a population-based study (Taichung Community Health Study, TCHS). Atherosclerosis 2010, 211:315-321.

10. Sharma M, McCarthy ET, Savin VJ, Lianos EA: Nitric oxide preserves the glomerular protein permeability barrier by antagonizing superoxide. Kidney Int 2005, 68:2735-2744.

11. Tofik R, Torffvit O, Rippe B, Bakoush O: Urine IgM-excretion as a prognostic marker for progression of type 2 diabetic nephropathy. Diabetes Res Clin Pract 2012, 95:139-144.

12. Tofik R, Torffvit O, Rippe B, Bakoush O: Increased urine IgM excretion predicts cardiovascular events in patients with type 1 diabetes nephropathy. BMC Med 2009, 7:39.

13. Bakoush O, Segelmark M, Torffvit O, Ohlsson S, Tencer J: Urine IgM excretion predicts outcome in ANCA-associated renal vasculitis. Nephrol Dial Transplant 2006, 21:1263-1269.

14. Tencer J, Thysell H, Grubb A: Analysis of proteinuria: reference limits for urine excretion of albumin, protein $\mathrm{HC}$, immunoglobulin $\mathrm{G}$, kappa- and lambda-immunoreactivity, orosomucoid and alpha 1-antitrypsin. Scand J Clin Lab Invest 1996, 56:691-700.

15. Nilsson PM, Engstrom G, Hedblad B: The metabolic syndrome and incidence of cardiovascular disease in non-diabetic subjects-a population-based study comparing three different definitions. Diabet Med 2007, 24:464-472.

16. Conroy RM, Pyorala K, Fitzgerald AP, Sans S, Menotti A, De Backer G, De Bacquer D, Ducimetiere P, Jousilahti $P$, Keil U, et al: Estimation of tenyear risk of fatal cardiovascular disease in Europe: the SCORE project. Eur Heart J 2003, 24:987-1003.

17. Ohlsson S, Bakoush O, Tencer J, Torffvit O, Segelmark M: Monocyte chemoattractant protein 1 is a prognostic marker in ANCA-associated small vessel vasculitis. Mediators Inflamm 2009, 2009:584916.

18. Haraldsson B, Nystrom J, Deen WM: Properties of the glomerular barrier and mechanisms of proteinuria. Physiol Rev 2008, 88:451-487.

19. Rippe C, Rippe A, Larsson A, Asgeirsson D, Rippe B: Nature of glomerular capillary permeability changes following acute renal ischemiareperfusion injury in rats. Am J Physiol 2006, 291:F1362-F1368.

20. Rippe C, Rippe A, Torffvit O, Rippe B: Size and charge selectivity of the glomerular filter in early experimental diabetes in rats. Am J Physiol Renal Physiol 2007, 293:F1533-F1538.

21. Axelsson J, Rippe A, Venturoli D, Sward P, Rippe B: Effects of early endotoxemia and dextran-induced anaphylaxis on the size selectivity of the glomerular filtration barrier in rats. Am J Physiol 2009, 296:F242-F248.

22. Axelsson J, Mahmutovic I, Rippe A, Rippe B: Loss of size selectivity of the glomerular filtration barrier in rats following laparotomy and muscle trauma. Am J Physiol 2009, 297:F577-F582.

23. Axelsson J, Rippe A, Rippe B: Acute hyperglycemia induces rapid, reversible increases in glomerular permeability in nondiabetic rats. Am J Physiol Renal Physiol 2010, 298:F1306-F1312.

24. Axelsson J, Rippe A, Rippe B: Transient and sustained increases in glomerular permeability following ANP infusion in rats. Am J Physiol Renal Physiol 2011, 300:F24-F30.

25. Axelsson J, Rippe A, Oberg CM, Rippe B: Rapid, dynamic changes in glomerular permeability to macromolecules during systemic angiotensin II (ANG II) infusion in rats. Am J Physiol Renal Physiol 2012, 303:F790-F799.

26. Tencer J, Frick IM, Oquist BW, Alm P, Rippe B: Size-selectivity of the glomerular barrier to high molecular weight proteins: upper size limitations of shunt pathways. Kidney Int 1998, 53:709-715. 
27. Kuo HK, Al Snih S, Kuo YF, Raji MA: Chronic inflammation, albuminuria, and functional disability in older adults with cardiovascular disease: the National Health and Nutrition Examination Survey, 1999-2008. Atherosclerosis 2012, 222:502-508.

28. Lindahl B, Diderholm E, Lagerqvist B, Venge P, Wallentin L, Investigators Fl: Mechanisms behind the prognostic value of troponin $\mathrm{T}$ in unstable coronary artery disease: a FRISC II substudy. J Am Coll Cardiol 2001, 38:979-986.

29. Al-Aqeedi RF, Abdullatef WK, Dabdoob W, Bener A, Albinali HA, Gehani A: The prevalence of metabolic syndrome components, individually and in combination, in male patients admitted with acute coronary syndrome, without previous diagnosis of diabetes mellitus. Libyan J Med 2013, 8:20185.

30. Than M, Cullen L, Reid CM, Lim SH, Aldous S, Ardagh MW, Peacock WF, Parsonage WA, Ho HF, Ko HF, et al: A 2-h diagnostic protocol to assess patients with chest pain symptoms in the Asia-Pacific region (ASPECT): a prospective observational validation study. Lancet 2011, 377:1077-1084.

31. Giallauria F, Lucci R, D'Agostino M, Vitelli A, Maresca L, Mancini M, Aurino M, Del Forno D, Giannuzzi P, Vigorito C: Two-year multicomprehensive secondary prevention program: favorable effects on cardiovascular functional capacity and coronary risk profile after acute myocardial infarction. J Cardiovasc Med 2009, 10:772-780.

\section{doi:10.1186/1471-2261-13-72}

Cite this article as: Tofik et al:: Increased urinary IgM excretion in patients with chest pain due to coronary artery disease. BMC Cardiovascular Disorders 2013 13:72.

\section{Submit your next manuscript to BioMed Central and take full advantage of:}

- Convenient online submission

- Thorough peer review

- No space constraints or color figure charges

- Immediate publication on acceptance

- Inclusion in PubMed, CAS, Scopus and Google Scholar

- Research which is freely available for redistribution 